Respiration 2013;86:352

DOI: $10.1159 / 000353428$

\section{Nasal High Flow and Respiratory Patterns: Determinants of Underlying Lung Functions - Are Complex Interactions Easily Controlled?}

\author{
Antonio M. Esquinas ${ }^{\mathrm{a}}$, Bhavisha Patel ${ }^{\mathrm{b}}$, Yalım Dikmen ${ }^{\mathrm{c}}$ \\ a Intensive Care Unit, Hospital Morales Meseguer, Murcia, Spain; \\ ${ }^{b}$ Department of Critical Care, MD Anderson Cancer Center, \\ The University of Texas, Houston, Tex., USA; ' Department of \\ Anesthesiology and Reanimation, Cerrahpasa Medical School, \\ Istanbul University, Istanbul, Turkey
}

Nasal high flow (nHF) therapy is a growing technology for respiratory support in different types of acute respiratory failure [1]. However, there are still some controversial issues and few studies in chronic pulmonary diseases [2]. Bräunlich et al. [3] analyzed the effects of nHF on the ventilatory patterns in three different clinical conditions: healthy volunteers, patients with chronic obstructive pulmonary disease (COPD), and patients with idiopathic pulmonary fibrosis (IPF). In this interesting and original study investigating ventilatory response, Bräunlich et al. show potential new applications for IPF and COPD.

We feel that some comments on the clinical practice implications of these observations are necessary. First, these results are clearly limited to the flow rate selected (20 liters/min) and may limit extrapolation to patients with poor baseline or an unstable pattern and a mild $\mathrm{PCO}_{2}$ level.

Second, the respiratory pattern and ventilatory response need some clarifications. The basal breathing pattern and respiratory rate (RR) of patients are not quite as high as compared to previous studies with $\mathrm{nHF}$ and may influence the extrapolations of these results, because the $\mathrm{RR}$ is a determinant of important parameters during $\mathrm{nHF}$, such as (1) end-inspiratory peak flow, end-expiratory pressure (EEP) and airway resistances, and (2) a stable breathing pattern of patients with the mouth closed. As regards these last parameters, EEP and effective $\mathrm{CO}_{2}$ control may be affected in an acute setting in COPD and IPD.

Third, there are some specific aspects related to these chronic lung diseases. (1) Some of these aspects concern the subgroup of IPF. We know that pulmonary function tests in IPF characteristically show a restrictive pattern for a low compliance, small lung volumes, and increased expiratory flow rates due to diffuse fibrosis
$[4,5]$. The application of nHF in IPF may influence low RR and higher tidal volumes in opposite directions as suggested by Bräunlich et al. [3]. There is no a clear clarification of these aspects. Additionally, IPF patients with low lung compliance may necessitate a higher level of flow than 20 liters/min to achieve more EEP pressure and best ventilatory response. These are remarkable aspects that may influence responses in IPF. (2) The authors describe an effective ventilatory response in COPD, but from a practical point of view, the application of $\mathrm{nHF}$ in an unstable and severe COPD patient could have a deleterious effect especially in those patients with severe COPD and lead to (a) an increase in basal airway resistances, (b) auto-positive EEP (auto-PEEP), (c) low expiratory tidal volumes, and (d) increased basal RR. In these cases, EEP generated by nHF may show a controversial ventilatory response. In normal conditions, 20 liters/min were associated with a lower EEP to balance auto-PEEP. We consider that a variable range of EEP by $\mathrm{nHF}$ with an unstable breathing pattern, airway resistance, and auto-PEEP may have adverse consequences.

Fourth, in IPF and COPD patients, linear relations among EEP and flow by nHF could be aggravated by severe lung obstruction and poor volumes, leakage around the nasal prongs, and an open mouth.

In conclusion, the effects of nHF remain limited to a small population of patients with very stable and restricted clinical conditions. It is necessary to know the predictors of response in IPF and COPD for short- and long-term indications.

\section{References}

1 Dysart K, Miller TL, Wolfson MR, Shaffer TH: Research in high flow therapy: mechanisms of action. Respir Med 2009;103:1400-1405.

2 Parke RL, Eccleston ML, McGuinness SP: The effects of flow on airway pressure during nasal high-flow oxygen therapy. Respir Care 2011;56: $1151-1155$

-3 Bräunlich J, Beyer D, Mai D, Hammerschmidt S, Seyfarth HJ, Wirtz H: Effects of nasal high flow on ventilation in volunteers, COPD and idiopathic pulmonary fibrosis patients. Respiration 2013;85:319-325.

4 Boyer A, Vargas F, Delacre M, Saint-Léger M, Clouzeau B, Hilbert G, Gruson D: Prognostic impact of high-flow nasal cannula oxygen supply in an ICU patient with pulmonary fibrosis complicated by acute respiratory failure. Intensive Care Med 2011;37:558-559.

5 Heathcote KL, Cockcroft DW, Fladeland DA, Fenton ME: Normal expiratory flow rate and lung volumes in patients with combined emphysema and interstitial lung disease: a case series and literature review. Can Respir J 2011;18:e73-e76.

\section{KARGER}

E-Mail karger@karger.com www.karger.com/res
(C) 2013 S. Karger AG, Basel

0025-7931/13/0864-0352\$38.00/0
Antonio M. Esquinas, MD, PhD, FCCP

Avenida Marques de los Velez s/n ES-30008 Murcia (Spain)

E-Mail antmesquinas@gmail.com 